\title{
The International Union against cancer celebrated the world cancer leaders' summit for the first time in Latin America
}

\author{
Francisco Javier Ochoa-Carrillo* \\ Instituto Nacional de Cancerología de México
}

From November 13 to 15, 2017, 350 world leaders from 60 countries gathered in Mexico City in the World Cancer Leaders' Summit, organized by the Union Internationale Contre le Cancer (UICC), with collaboration of the Federal Ministry of Health and the National Institute of Cancer of Mexico, with the leadership of Abelardo A. Meneses, its Director General, and with unrestricted support of the Mexican Government through the President of the Republic, Enrique Peña Nieto.

The event started by illuminating the historic and emblematic Monument to Independence with orange light (UICC official color) to symbolize the solidarity of Mexico City Government and inhabitants with the fight against cancer.

The event was opened by the UICC President, Prof. Sanchia Aranda, who welcomed a group of distinguished guests, including the President of Mexico, Enrique Peña Nieto, the President of Uruguay, Tabaré Vázquez, Her Majesty Queen Letizia of Spain, Mexico's First Lady Angélica Rivera de Peña, the Vice-president of Argentina, Gabriela Michetti, Belize's First Lady Kim Simplis Barrow and Her Royal Highness Princess Dina Mired of Jordan, UICC President-elect. The event was also attended by Mexico City's Major Miguel Ángel Mancera, Mexico's Federal Secretary of Health, José Narro Robles, Mexico City's Secretary of Health, Armando Ahued Ortega and Salomón Chertorivski Woldenberg, Mexico City's Secretary of Economic Development. All of them had an important participation and shared their successful experiences in the struggle to detect cancer, as well as in implementing successful policies to preserve and make health programs available to the population.

Several health Ministers of different countries were also present, as well as prominent leaders and the Majors of numerous cities. The UICC members were more than one third of participants in the Summit, representing 102 members of 45 countries. The event was hosted by Televisa news anchor Paola Rojas.

The summit's participants discussed about the best way to establish global agreements in order to be entirely operational and to offer solutions against cancer that efficiently, sufficiently and expeditiously reach the entire world population. Efficiency in the implementation of nation-wide cancer control was discussed in one of the forums.

The topic of the summit, "Cities driving change", was an opportunity to show inspiring examples on how cities can assume the leadership to undertake sustainable solutions and improve access to cancer treatment and care in their countries.

Discussions were dynamic and optimistic, focusing on how countries and cities all over the world can contribute to cancer resolution by accelerating the impact on cancer control and making important progresses towards the global goal of a $25 \%$ reduction of premature deaths from cancer and other non-communicable diseases (NCDs) by 2025.

In addition to the Summit's hosts, the UICC was associated with the International Agency for Research on
Correspondence:

${ }^{*}$ F.J. Ochoa-Carrillo

E-mail: ochoacarrillo@ prodigy.net.mx DOI: 10.24875/j.gamo.M18000153
Available online: $24-02-2018$ Gac Mex Oncol. 2017;16(6):303-305 www.gamo-smeo.com 1665-9201 / @ 2017 Sociedad Mexicana de Oncología. Published by Permanyer México. This is an Open Access article under the terms of the CC BY-NC-ND license (http://creativecommons.org/licenses/by-nc-nd/4.0/). 
Cancer (IARC), the International Atomic Energy Agency (IAEA) and the World Health Organization (WHO); in addition, it was supported by means of the sponsorship of 20 health leading organizations, which contributed to a productive, warm and successful event.

The President of Uruguay and "City Cancer Challenge" Ambassador, President Tabaré Vázquez, gave the opening speech, where he stated how cancer is the great health challenge of our times, since it disproportionally affects a vulnerable majority in the world. He emphasized on the power of cities to reduce mortality by means of accurate and direct information, with strategies for early diagnosis, clinical research, optimal treatment and palliative care, particularly addressing the importance of tobacco control and better awareness and education on the subject.

The President of Mexico, Enrique Peña Nieto, emphasized that his government is committed with civil society and with the international community with the purpose to guarantee public policies on fight against cancer at the municipal, state and national levels. He underscored that "health is a fundamental human right, and universal access to health services has therefore to be ensured, with this being one of our duties as State". The president expressed that, already in June 2017, Mexico approved the National Cancer Registry. As a second step, in line with the country's national priorities and international commitments, the National Plan Against Cancer should be soon approved.

Gabriela Michetti, Vice-president of Argentina, referred to the importance of including the design of policies that enable governments to speak the same language in the Sustainable Development Goals in order to improve the quality of life and wellbeing by means of greater cohesion and collaboration at all levels of government and with a group of new partners.

The WHO Director General, Etienne Krug, underscored the critical need of an action against cancer, given that in the course of the morning's discussions, around 3,000 people in the entire world would have been diagnosed with cancer and more than 2,000 would have died. "The marked global inequities in the access to cancer early detection, treatment and care services are inacceptable".

Etienne Krug urged the Summit' participants to translate global promises into specific actions. Undersoring the advice and guidelines provided to governments by the WHO in order to implement cost-effective interventions against cancer, he announced that the WHO is working on a cost tool focused on global policies directed to a better knowledge about cancer, which will be launched in 2019.

Tedros Adhanom Ghebreyesus, Director General of the WHO, in a recorded speech, stressed on the critical importance of developing a universal health coverage that guarantees that people, regardless of their localization or income, can access to the services they require. He suggested that our cities have a unique position to transform the fight against cancer and other NCDs. They should be incubators of innovative policies that enable offering accessible and affordable care for all.

The welcome message to the debate forums was in charge of Abelardo A. Meneses García, who also indicated the objectives and format of the sessions, with Alejandro Mohar Betancourt, former director of the National Institute of Cancer (INCan), also participating.

Subsequently, the first discussion panel was carried out, addressing the subject "Leadership and mobilization of Civil Society Organizations (CSO) in favor of the Comprehensive Plan for Cancer Control and Prevention in Mexico", with the participation of Mayra Galindo, Director General of the Mexican Association of Fight Against Cancer (AMLCC), Eliza Puente, Director General of the Mexican Association for the Fight Against Breast Cancer, Isabelle Aloi-Timeus, President of Asociación Salvati, Alma América Ariyoshi, Chairwoman of Asociación George Papanicolau, and Alberto Torres, Chairman of Casa de la Amistad. The debate was masterfully coordinated by Karla Iberia Sánchez, presenter and investigative journalist from Televisa México.

Next, Francisco Javier Ochoa Carrillo, surgical oncologist at INCan and AMLCC current Chairman, discussed about "Mexican CSOs contribution in matters of public policies for cancer control". His presentation motivated key questions in the audience and stimulated the attendee's participation.

During this activity, the document "CSOs in the face of the Comprehensive Program for Cancer Prevention and Control in Mexico" was read out, with the participation of Patricia Mondragón, Respirando con Valor Chairwoman, Ana María López, General Manager of Prueba para la Vida, Preventive Oncology International, Mexico, María Alejandre, Chairwoman of the Mexican Association for the Aid of Children with Cancer, Luz María Mendoza, Fundación Pasteur Chairwoman and Francisco Freyra, Director General of Fundación Fomento de Desarrollo.

The conclusions and the call for action for the Comprehensive Program for Cancer Prevention and Control 
in Mexico were offered by Laura Suchil, Head of INCan Department of Institutional Relations.

This meeting set a precedent by the number of high-level participants and renowned associations of our country, which have generated individual efforts in the fight against cancer, but that have the capability to unite for a specific project such as the one that was addressed in the course of this session.

This event was the first in its class to take place in the Latin American region and was carried out thanks to a coordinated effort by INCan and UICC, with the participation and support of key partners for its development, such as the WHO, the IAEA and the IARC, as well as health ministers and important public health leaders.

This Summit was acknowledged by the UICC as the most successful of its history, since it had the participation of over 350 leaders from more than 60 countries, an impact of more than 1,100 articles published in national and international means of communication, 110 media representatives attending the event, and a reach of 7,000 million opportunities of having been seen, read or listened in the coverage of the great celebrities that were gathered, such as her Majesty Queen Letizia of Spain and other distinguished personalities. 